\title{
Effects of Potassium on Ammonia Transport by Medullary Thick Ascending Limb of the Rat
}

David W. Good

Renal-Electrolyte Physiology Laboratory, Departments of Physiology \& Biophysics and Internal Medicine, University of Texas Medical Branch, Galveston, Texas 77550

\begin{abstract}
Renal ammonium excretion is increased by potassium depletion and reduced by potassium loading. To determine whether changes in potassium concentration would alter ammonia transport in the medullary thick ascending limb (MAL), tubules from rats were perfused in vitro and effects of changes in $K$ concentration within the physiological range (4-24 $\mathrm{mM}$ ) were evaluated. Increasing $\mathrm{K}$ concentration from 4 to $24 \mathrm{mM}$ in perfusate and bath inhibited total ammonia absorption by $50 \%$ and reduced the steady-state transepithelial $\mathrm{NH}_{4}^{+}$concentration gradient. The inhibition of total ammonia absorption was reversible and occurred when $K$ replaced either $\mathrm{Na}$ or $\boldsymbol{N}$ methyl-D-glucamine. Increasing $\mathbf{K}$ concentration in the luminal perfusate alone gave similar inhibition of total ammonia absorption. At 1-2 $\mathrm{nl} / \mathrm{min}$ per $\mathrm{mm}$ perfusion rate, increasing $\mathrm{K}$ concentration in perfusion and bathing solutions had no significant effect on transepithelial voltage. With either 4 or $24 \mathrm{mM}$ $K$ in perfusate and bath, an increase in luminal perfusion rate markedly increased total ammonia absorption. Thus, both potassium concentration and luminal flow rate are important factors capable of regulating total ammonia transport by the MAL. Changes in systemic potassium balance may influence renal ammonium excretion by affecting $\mathrm{NH}_{4}^{+}$absorption in the MAL and altering the transfer of ammonia from loops of Henle to medullary collecting ducts.
\end{abstract}

\section{Introduction}

Changes in potassium balance exert important effects on renal net acid excretion and are thought to contribute to the acidbase disorders that accompany a variety of pathologic conditions such as chronic renal insufficiency, mineralocorticoid imbalance, and gastrointestinal fluid loss $(1,2)$. An important way in which potassium influences acid-base balance is by modulating net acid excretion through effects on renal ammonium excretion. Potassium depletion is associated with increased ammonium excretion and metabolic alkalosis, whereas potassium retention and hyperkalemia are associated with decreased ammonium excretion and metabolic acidosis

Address correspondence and reprint requests to: Dr. Good, Renal Electrolyte Physiology Laboratory, John Sealy Hospital, Rm. 4.200, Rt. E-62, University of Texas Medical Branch, Galveston, TX 77550.

Results of these experiments were presented in part at the 19th Annual Meeting of the American Society of Nephrology (1987. Kidney Int. 31:408) and at the 10th International Congress of Nephrology, July 1987.

Received for publication 27 May 1987.

J. Clin. Invest.

(c) The American Society for Clinical Investigation, Inc. $0021-9738 / 87 / 11 / 1358 / 08 \quad \$ 2.00$

Volume 80, November $1987,1358-1365$
(1-3). This relationship is due, in part, to effects of potassium on renal ammonia production (3). However, changes in ammonium excretion may also result from changes in the tubule transport processes that channel synthesized ammonia ${ }^{1}$ into the final urine (4). The possibility that direct effects of potassium on renal tubule ammonia transport, independent of effects on ammonia production, may contribute to the relation between potassium balance and ammonium excretion has not previously been considered. The purpose of the present study, therefore, was to determine whether changes in potassium concentration would modify ammonia transport in the medullary thick ascending limb. This segment was studied because $\mathrm{NH}_{4}^{+}$absorption by thick ascending limbs is thought to play an important role in promoting medullary ammonia accumulation and urinary ammonium excretion $(4,5)$ and because potassium concentrations in the renal medulla vary over a wide range when potassium intake is changed (6-8). In vitro microperfusion methods were used so that effects of potassium on ammonia transport could be examined in the absence of changes in systemic factors such as plasma $\mathrm{pH}$, adrenal steroid hormone levels, and renal blood flow. The results indicate that an increase in potassium concentration markedly inhibits total ammonia absorption by the medullary thick ascending limb of the rat. This effect may provide an additional explanation for the relationship between systemic potassium balance and renal ammonium excretion.

\section{Methods}

Pathogen-free male Sprague-Dawley rats $(60-90 \mathrm{~g}$ body wt; Taconic Farms, Inc., Germantown, NY) received commercial rat chow (NIH 31 diet, Ziegler Bros., Inc., Gardners, PA) and tap water up to the time of experiments. All rats were injected intraperitoneally with furosemide ( $2 \mathrm{mg}$ ) 10-15 min before experiments to improve the viability of medullary thick ascending limbs in vitro (5). The rats were anesthetized by intraperitoneal injection of sodium pentobarbital $(50 \mathrm{mg} / \mathrm{kg}$ body wt). The abdominal cavity was opened by a midline incision and the left kidney was bathed in situ for 1-2 min with ice-cold dissecting solution. This procedure has been shown to preserve the viability of rat proximal straight tubules in vitro (9), and was used in the present study to prevent tubule damage that may result from warm ischemia. After cooling, the kidney was removed and sliced along the cortical-medullary axis. Medullary thick ascending limbs were dissected from the slices at $10^{\circ} \mathrm{C}$ in a solution that contained (in $\mathrm{mM}$ ): $145 \mathrm{NaCl}, 2.0$ $\mathrm{K}_{2} \mathrm{HPO}_{4}, 1.2 \mathrm{Na}_{2} \mathrm{SO}_{4}, 1.0 \mathrm{CaCl}_{2}, 1.0 \mathrm{Ca}$ lactate, $0.5 \mathrm{Mg}$ citrate, and 5.5 glucose. The dissection fluid was gassed with $100 \%$ oxygen and titrated to pH 7.4. Medullary thick ascending limbs were dissected from the inner stripe of the outer medulla and averaged $\sim 0.5 \mathrm{~mm}$ in length.

After dissection, the tubules were transferred to a temperaturecontrolled chamber and perfused in vitro at $37^{\circ} \mathrm{C}$ with concentric pipettes as previously described $(5,10)$. The tubules were allowed to

1. In this paper, the terms ammonia and total ammonia refer to the sum of ammonium ion $\left(\mathrm{NH}_{4}^{+}\right)$and free-base ammonia $\left(\mathrm{NH}_{3}\right)$. 
Table I. Composition of Perfusion and Bathing Solutions

\begin{tabular}{rrrllll}
\hline & {$[\mathrm{Na}]$} & {$[\mathrm{K}]$} & {$[\mathrm{Cl}]$} & {$\left[\mathrm{NH}_{4}\right]$} & {$\left[\mathrm{HCO}_{3}\right]$} & $\begin{array}{l}\text { [N-methyl- } \\
\text { D-glucamine] }\end{array}$ \\
\hline I & 146 & 4 & 122 & 4 & 25 & 0 \\
II & 126 & 24 & 122 & 4 & 25 & 0 \\
III & 146 & 4 & 142 & 4 & 25 & 20 \\
IV & 146 & 24 & 142 & 4 & 25 & 0 \\
V & 146 & 4 & 120 & 2 & 25 & 0 \\
VI & 126 & 24 & 120 & 2 & 25 & 0
\end{tabular}

All values are in $\mathrm{mM}$. Each solution additionally contained (mM): $2.0 \mathrm{Ca}, 1.5 \mathrm{Mg}, 2.0$ phosphate, $1.2 \mathrm{SO}_{4}, 1.0$ citrate, 2.0 lactate, 5.5 glucose.

equilibrate for 10-15 min after warming and the perfusion pressure was adjusted to establish a steady luminal flow rate. Tubule fluid emerging from the distal end of the tubules was collected under oil for analysis of total ammonia concentration. The fluid was collected for timed intervals into calibrated constriction pipettes $(7-16 \mathrm{nl})$ for determination of volume flow rates. In most experiments, the tubule perfusion rate was $1-2 \mathrm{nl} / \mathrm{min}$ per $\mathrm{mm}$.

Six perfusion and bathing solutions were used (Table I). Solutions I-IV were used to test the effects of increasing potassium concentration on total ammonia transport rate. The potassium concentration in perfusate and bath was increased by substituting potassium for sodium (solutions I and II) or $\mathrm{N}$-methyl-D-glucamine (solutions III and IV). Solutions V and VI were used to determine steady state luminal total ammonia concentrations and were identical to solutions I and II except that they contained $2.0 \mathrm{mM} \mathrm{NH}_{4} \mathrm{Cl}$. All of the solutions were equilibrated with $95 \% \mathrm{O}_{2}, 5 \% \mathrm{CO}_{2}$ and were $\mathrm{pH} 7.47-7.48$ at $37^{\circ} \mathrm{C}$. Measured osmolalities were $293 \mathrm{mosmol} / \mathrm{kg} \mathrm{H}_{2} \mathrm{O}$ for solutions I and II, $328 \mathrm{mosmol} / \mathrm{kg} \mathrm{H}_{2} \mathrm{O}$ for solutions III and IV and $290 \mathrm{mosmol} / \mathrm{kg} \mathrm{H}_{2} \mathrm{O}$ for solutions V and VI. Sodium, potassium, chloride, and total $\mathrm{CO}_{2}$ concentrations were measured routinely on bulk solutions. The oxygen and $\mathrm{CO}_{2}$ tensions in the bath were maintained constant using a continuous bath exchange system as previously described (5). The bathing solutions were bubbled continuously in a reservoir with $95 \%$ $\mathrm{O}_{2}, 5 \% \mathrm{CO}_{2}$, and the perfusion chamber was suffused with the same gas mixture. The equilibrated bath solutions were delivered to the perfusion chamber at a rate of $0.4 \mathrm{ml} / \mathrm{min}$ through a line that was jacketed with $95 \% \mathrm{O}_{2}, 5 \% \mathrm{CO}_{2}$ gas.

Transepithelial voltage of the tubules was measured between calomel cells as previously described (5). For experiments in which the perfusion and bathing solutions differed in ionic composition, the measured transepithelial voltage was corrected for the change in liquid junction voltage. Corrections were required only for experiments involving solutions I and II. The calculated liquid junction voltage (solution I vs. solution II) was $0.6 \mathrm{mV}$. This value was added to or subtracted from the measured voltages as appropriate to obtain the actual transepithelial voltages reported in Results.

Sodium and potassium concentrations in bulk solutions were measured by flame-photometry (model 435, Corning Medical and Scientific Instruments, Inc., Medfield, MA). Chloride concentrations were measured by electrometric titration (Buchler-Cotlove, Fort Lee, $\mathrm{NJ}$ ). Osmolality of solutions was measured cryoscopically (model 3DII, Advanced Instruments, Inc., Needham Heights, MA). Total carbon dioxide concentrations in bulk solutions were measured using a carbon dioxide analyzer (Corning Medical \& Scientific Instruments, Inc.).

Total ammonia concentrations in perfusion and bathing solutions and in collected tubule fluid were measured by microfluorometry using the glutamate dehydrogenase reaction as previously described (5, 11). Since there is no net fluid transport in rat thick ascending limbs (5, $12,13)$, absolute rates of total ammonia transport $\left(J_{\mathrm{Am}}, \mathrm{pmol} / \mathrm{min}\right.$ per $\mathrm{mm}$ ) were calculated as $J_{\mathrm{Am}}=V\left(C_{\mathrm{O}}-C_{\mathrm{L}}\right) / L$, where $V$ is fluid collection rate $(\mathrm{nl} / \mathrm{min}), C$ is total ammonia concentration in perfused $(O)$ and collected $(L)$ fluid $(\mathrm{mM})$ and $L$ is perfused tubule length $(\mathrm{mm})$. Positive values indicate net total ammonia absorption. A mean collected total ammonia concentration, fluid collection rate and total ammonia transport rate was calculated for each experimental condition studied in a given tubule. These single tubule values were averaged to obtain the group means presented in the tables ( $n$, number of tubules). Differences between means were evaluated using the $t$ test for paired or unpaired data as appropriate. A $P$ value of $<0.05$ was regarded as indicating significance.

\section{Results}

The effect of increasing the potassium concentration in perfusate and bath from 4 to $24 \mathrm{mM}$ on total ammonia transport is shown in Table II (mean values) and Fig. 1 (individual data). In these experiments, potassium replaced sodium. When the concentration of potassium in lumen and bath was increased, the collected total ammonia concentration rose from 1.8 to 2.8 mM (Fig. 1, closed circles) and the total ammonia absorption rate was reduced (Table II). Increasing the potassium concentration in perfusate and bath had no significant effect on transepithelial voltage (Fig. 1, Table II).

To determine whether the inhibition of total ammonia absorption in experiments in Table II was due to the increase in potassium concentration or to the decrease in sodium concen-

Table II. Effect of Increasing Potassium Concentration in Perfusate and Bath (Na Replaced with K) on Total Ammonia Transport

\begin{tabular}{|c|c|c|c|c|c|c|}
\hline \multicolumn{2}{|c|}{ Perfusate/bath } & \multirow[b]{2}{*}{$v$} & \multicolumn{2}{|l|}{ [Am] } & \multirow[b]{2}{*}{$J_{\mathbf{A m}}$} & \multirow[b]{2}{*}{$V_{\mathrm{TE}}$} \\
\hline Solutions & {$[\mathrm{K}]$} & & Perfused & Collected & & \\
\hline & $m M$ & $\mathrm{nl} / \mathrm{min} / \mathrm{mm}$ & $m M$ & $m M$ & $\mathrm{pmol} / \mathrm{min} / \mathrm{mm}$ & $m V$ \\
\hline I/I & $4 / 4$ & $1.8 \pm 0.2$ & $4.0 \pm 0.03$ & $1.8 \pm 0.1^{*}$ & $4.1 \pm 0.4$ & $5.4 \pm 0.8$ \\
\hline \multirow[t]{2}{*}{ II/II } & $24 / 24$ & $1.8 \pm 0.2$ & $4.1 \pm 0.03$ & $2.8 \pm 0.1^{*}$ & $2.4 \pm 0.3$ & $6.8 \pm 0.7$ \\
\hline & $P$ & NS & NS & $<0.001$ & $<0.001$ & NS \\
\hline
\end{tabular}

Values are means \pm SE. Number of experiments $=11$. Mean tubule length $=0.51 \pm 0.03 \mathrm{~mm}$. Perfusion and bathing solutions correspond to those in Table I. $V$ is fluid collection rate, [Am] is total ammonia concentration, $J_{\mathrm{Am}}$ is absolute rate of total ammonia absorption, and $V_{\mathrm{TE}}$ is transepithelial voltage, oriented lumen positive with respect to bath. [Am] in the bath was $4.0 \pm 0.03 \mathrm{mM}$ with solution I and $4.0 \pm 0.03 \mathrm{mM}$ with solution II. $P$ values are for $4 \mathrm{~K}$ vs. $24 \mathrm{~K}$ (paired $t$ test); NS indicates no significant difference. * Collected [Am] significantly different from perfused (paired $t$ test). 

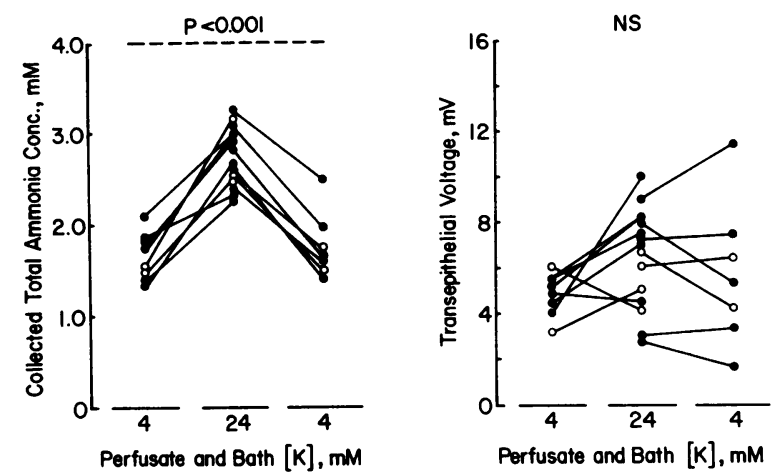

Figure 1. Effects of increasing potassium concentration in perfusate and bath on collected total ammonia concentration and transepithelial voltage in medullary thick ascending limbs. Potassium replaced either sodium (closed circles) or $N$-methyl-D-glucamine (open circles). Closed and open circles are mean values for single tubules. Lines connect paired measurements made in the same tubule. (Broken line) Total ammonia concentration in perfusate and bath $(4 \mathrm{mM}) . P$ values determined by paired $t$ test; NS indicates no significant difference.

tration, a second series of experiments was performed in which potassium replaced $N$-methyl-D-glucamine and sodium concentration was held constant. The results are shown in Table III and Fig. 1 (open circles). Increasing potassium concentration in the perfusate and bath again caused a reversible increase in collected total ammonia concentration and a significant reduction in total ammonia absorption rate. Increasing the potassium concentration at constant sodium concentra- tion had no detectable effect on transepithelial voltage (Table III, Fig. 1).

The effects of increasing potassium concentration in the luminal perfusate alone are shown in Table IV and Fig. 2. Increasing potassium in the perfusate from 4 to $24 \mathrm{mM}$ increased collected total ammonia concentration and reduced total ammonia absorption rate but had no significant effect on transepithelial voltage. Thus, increasing the potassium concentration in the lumen alone gave results similar to those obtained when potassium was increased in both lumen and bath (Tables II and III).

To determine whether an increase in potassium concentration would affect the limiting luminal total ammonia concentration, tubules were perfused at slow rates with $2.0 \mathrm{mM}$ $\mathrm{NH}_{4} \mathrm{Cl}$ in the perfusate and $4.0 \mathrm{mM} \mathrm{NH}_{4} \mathrm{Cl}$ in the bath. The results are shown in Table $\mathrm{V}$ and Fig. 3. When tubules were studied with $4 \mathrm{mM}$ potassium in perfusate and bath, total ammonia concentration fell significantly along the tubule lumen from $2.0 \mathrm{mM}$ in the perfusate to $1.4 \mathrm{mM}$ in the collected fluid (Table V, Fig. 3). ${ }^{2}$ In contrast, when tubules were studied with $24 \mathrm{mM}$ potassium in perfusate and bath, total ammonia concentration rose significantly along the tubule

2. In six additional tubules perfused with $1.5 \mathrm{mM} \mathrm{NH}_{4} \mathrm{Cl}$ in perfusate and $4.0 \mathrm{mM} \mathrm{NH}_{4} \mathrm{Cl}$ in bath, mean collected total ammonia concentration was $1.6 \pm 0.1 \mathrm{mM}$. This concentration did not differ significantly from the collected concentration of $1.4 \mathrm{mM}$ obtained with the $2.0 \mathrm{mM} \mathrm{NH}_{4} \mathrm{Cl}$ perfusate. Because reducing total ammonia concentration in the perfusate did not affect the total ammonia concentration in collected fluid, the collected total ammonia concentrations reported in Table $\mathrm{V}$ are taken to represent steady state values.

Table III. Effect of Increasing Potassium Concentration in Perfusate and Bath (N-methyl-D-glucamine Replaced with Potassium) on Total Ammonia Transport

\begin{tabular}{|c|c|c|c|c|c|c|}
\hline \multicolumn{2}{|c|}{ Perfusate/bath } & \multirow[b]{2}{*}{$\mathrm{v}$} & \multicolumn{2}{|l|}{ [Am] } & \multirow[b]{2}{*}{$J_{\mathrm{Am}}$} & \multirow[b]{2}{*}{$V_{\mathrm{TE}}$} \\
\hline Solutions & {$[\mathrm{K}]$} & & Perfused & Collected & & \\
\hline & $m M$ & $\mathrm{nl} / \mathrm{min} / \mathrm{mm}$ & $m M$ & $m M$ & $\mathrm{pmol} / \mathrm{min} / \mathrm{mm}$ & $m V$ \\
\hline III/III & $4 / 4$ & $1.9 \pm 0.4$ & $4.1 \pm 0.12$ & $1.6 \pm 0.1^{*}$ & $4.7 \pm 0.8$ & $5.1 \pm 0.8$ \\
\hline \multirow[t]{2}{*}{ IV/IV } & $24 / 24$ & $1.9 \pm 0.4$ & $4.1 \pm 0.04$ & $2.7 \pm 0.2^{*}$ & $2.7 \pm 0.7$ & $5.6 \pm 0.6$ \\
\hline & $P$ & NS & NS & $<0.025$ & $<0.10$ & NS \\
\hline
\end{tabular}

Values are means $\pm \mathrm{SE}$. Number of experiments $=4$. Mean tubule length $=0.50 \pm 0.03 \mathrm{~mm}$. [Am] in bath solutions was $4.0 \pm 0.07 \mathrm{mM} . P$ values are for $4 \mathrm{~K}$ vs. $24 \mathrm{~K}$ (paired $t$ test). Table headings, NS and ${ }^{*}$ as in Table II.

Table IV. Effect of Increasing Potassium Concentration in Luminal Perfusate on Total Ammonia Transport

\begin{tabular}{|c|c|c|c|c|c|c|}
\hline \multicolumn{2}{|c|}{ Perfusate/bath } & \multirow[b]{2}{*}{$V$} & \multicolumn{2}{|l|}{ [Am] } & \multirow[b]{2}{*}{$J_{\mathrm{Am}}$} & \multirow[b]{2}{*}{$V_{\mathrm{TE}}$} \\
\hline Solutions & {$[\mathrm{K}]$} & & Perfused & Collected & & \\
\hline & $m M$ & $\mathrm{nl} / \mathrm{min} / \mathrm{mm}$ & $m M$ & $m M$ & $\mathrm{pmol} / \mathrm{min} / \mathrm{mm}$ & $m V$ \\
\hline $\mathrm{I} / \mathrm{I}$ & $4 / 4$ & $2.3 \pm 0.2$ & $4.0 \pm 0.02$ & $1.6 \pm 0.1^{*}$ & $5.4 \pm 0.6$ & $6.1 \pm 0.8$ \\
\hline \multirow[t]{2}{*}{ II/I } & $24 / 4$ & $2.2 \pm 0.2$ & $4.0 \pm 0.02$ & $2.3 \pm 0.1^{*}$ & $3.8 \pm 0.4$ & $7.3 \pm 1.0$ \\
\hline & $P$ & NS & NS & $<0.001$ & $<0.001$ & NS \\
\hline
\end{tabular}

Values are means \pm SE. Number of experiments $=13$. Mean tubule length $=0.50 \pm 0.02 \mathrm{~mm}$. [Am] in bath was $4.0 \pm 0.02 \mathrm{mM} . P$ values are for 4 $\mathrm{K}$ vs. $24 \mathrm{~K}$ (paired $t$ test). Table headings, NS and ${ }^{*}$ as in Table II. 

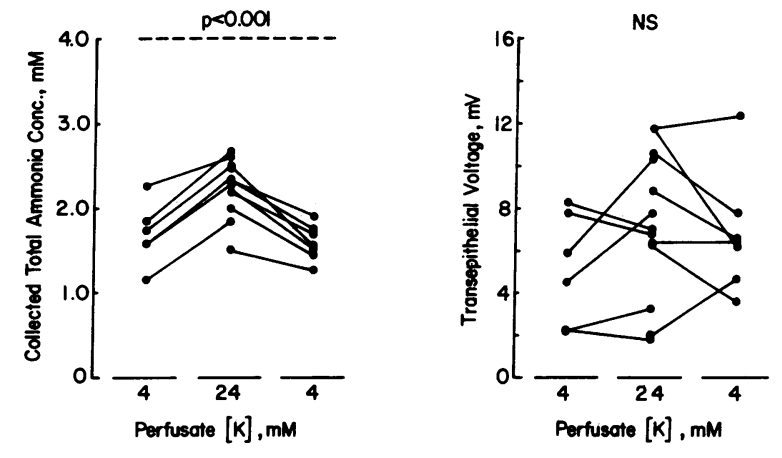

Figure 2. Effects of increasing potassium concentration in luminal perfusate on collected total ammonia concentration and transepithelial voltage in medullary thick ascending limbs. Closed circles, lines, and $P$ values as in Fig. 1.

lumen from $2.0 \mathrm{mM}$ in the perfusate to $2.2 \mathrm{mM}$ in the collected fluid (Table V, Fig. 3). Thus, increasing the potassium concentration in the perfusate and bath reduced the maximum transepithelial $\mathrm{NH}_{4}^{+}$concentration gradient that could be generated and maintained by the medullary thick ascending limb. Increasing the potassium concentration had no significant effect on transepithelial voltage in tubules perfused with $2.0 \mathrm{mM}$ $\mathrm{NH}_{4} \mathrm{Cl}$ (Table V).

In the experiments shown in Tables II-IV, total ammonia concentration fell along the tubule lumen to values approaching the collected total ammonia concentrations measured under steady state conditions (Table V). Because the fall in lumen total ammonia concentration would tend to limit the rate of total ammonia absorption, the total ammonia transport rates reported in Tables II-IV represent minimum estimates of the tubules ability to absorb ammonia. In order to obtain a more accurate estimate of the total ammonia transport capacity in medullary thick ascending limbs, and in order to examine the effect of potassium concentration on ammonia transport rate under optimal conditions, tubules were perfused at a higher flow rate to minimize the fall in luminal total ammonia concentration. The results are shown in Table VI and Fig. 4. In tubules studied with either 4 or $24 \mathrm{mM}$ potassium in perfusate and bath, the total ammonia absorption rate at $10 \mathrm{nl} / \mathrm{min}$ per $\mathrm{mm}$ was three to four times higher than rates measured at 2 $\mathrm{nl} / \mathrm{min}$ per $\mathrm{mm}$ (Table II) $(P<0.001$, unpaired $t$ test). At the higher flow rate, increasing potassium concentration in the perfusate and bath reduced the total ammonia absorption rate

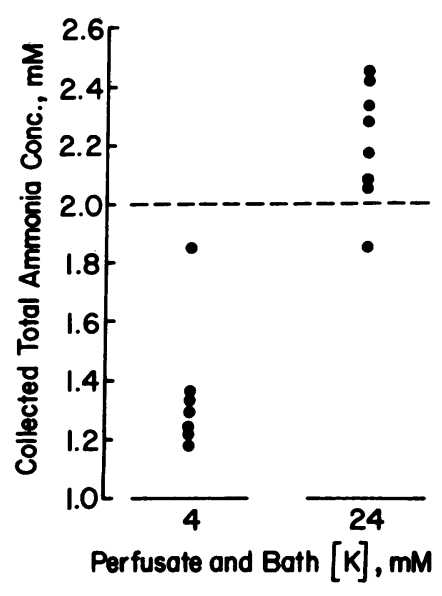

Figure 3. Effect of increasing potassium concentration in perfusate and bath on limiting luminal total ammonia concentration in medullary thick ascending limbs. Tubules were perfused with $2.0 \mathrm{mM} \mathrm{NH}_{4} \mathrm{Cl}$ in perfusate (broken line) and $4.0 \mathrm{mM} \mathrm{NH}_{4} \mathrm{Cl}$ in bath.

Closed circles are mean values for single tubules.

by $50 \%$ and increased the transepithelial voltage (Table VI, Fig. 4). The effects of increasing potassium concentration on total ammonia absorption rate and transepithelial voltage were reversible (Fig. 4).

\section{Discussion}

Changes in potassium balance have been implicated in the pathogenesis of acid-base disturbances in a variety of clinical disorders. Potassium depletion is thought to contribute to the maintenance of metabolic alkalosis in conditions associated with chloride depletion, mineralocorticoid excess, and gastrointestinal fluid loss. In contrast, potassium retention and hyperkalemia may be contributing factors in the development of the metabolic acidosis that typically accompanies advanced renal insufficiency and mineralocorticoid deficiency $(1,2)$. These effects are due, in part, to an important influence of potassium on renal ammonium excretion (1-3). Ammonium excretion decreases when potassium intake is high and increases when potassium intake is low $(1,3)$. This relationship is thought to be due primarily to direct effects of potassium on renal ammonia production $(1,3)$. Potassium may also affect renal ammonium excretion indirectly by affecting plasma $\mathrm{pH}$, proximal tubule acidification, and medullary blood flow (1-3). In the present study, an additional explanation for the influence of potassium balance on ammonium excretion has been considered, namely, that changes in potassium concentration may directly affect renal tubule ammonia transport. The re-

Table V. Effect of Increasing Potassium Concentration on Limiting Luminal Total Ammonia Concentration

\begin{tabular}{|c|c|c|c|c|c|}
\hline \multicolumn{2}{|c|}{ Perfusate/bath } & \multirow[b]{2}{*}{$V$} & \multicolumn{2}{|l|}{ [Am] } & \multirow[b]{2}{*}{$V_{\mathbf{T E}}$} \\
\hline Solutions & {$[\mathrm{K}]$} & & Perfused & Collected & \\
\hline & $m M$ & $\mathrm{nl} / \mathrm{min} / \mathrm{mm}$ & $m M$ & $m M$ & $m V$ \\
\hline V/I (7) & $4 / 4$ & $1.2 \pm 0.1$ & $2.0 \pm 0.02$ & $1.4 \pm 0.1^{*}$ & $11.6 \pm 1.2$ \\
\hline \multirow[t]{2}{*}{ VI/II (8) } & $24 / 24$ & $1.0 \pm 0.1$ & $2.0 \pm 0.03$ & $2.2 \pm 0.1^{*}$ & $11.7 \pm 0.9$ \\
\hline & $P$ & NS & NS & $<0.001$ & NS \\
\hline
\end{tabular}

Values are means \pm SE. Numbers in parentheses indicate numbers of tubules. Mean tubule length $=0.49 \pm 0.05 \mathrm{~mm}$ in $4 \mathrm{~K}$ experiments and $0.51 \pm 0.03 \mathrm{~mm}$ in $24 \mathrm{~K}$ experiments. [Am] in bath was $4.0 \pm 0.04 \mathrm{mM}$ (solution I) and $4.0 \pm 0.08 \mathrm{mM}$ (solution II). $P$ values are for $4 \mathrm{~K}$ vs. $24 \mathrm{~K}$ (unpaired $t$ test). Table headings, NS and * as in Table II. 
Table VI. Effect of Potassium Concentration on Total Ammonia Transport Rate at High Perfusion Rate

\begin{tabular}{|c|c|c|c|c|c|c|}
\hline \multicolumn{2}{|c|}{ Perfusate/bath } & \multirow[b]{2}{*}{$V$} & \multicolumn{2}{|l|}{ [Am] } & \multirow[b]{2}{*}{$J_{\mathbf{A m}}$} & \multirow[b]{2}{*}{$V_{\mathrm{TE}}$} \\
\hline Solutions & [K] & & Perfused & Collected & & \\
\hline & $m M$ & $\mathrm{nl} / \mathrm{min} / \mathrm{mm}$ & $m M$ & $m M$ & $\mathrm{pmol} / \mathrm{min} / \mathrm{mm}$ & $m V$ \\
\hline $\mathrm{I} / \mathrm{I}$ & $4 / 4$ & $10.6 \pm 2.2$ & $4.0 \pm 0.04$ & $2.4 \pm 0.1^{*}$ & $15.8 \pm 1.7$ & $2.4 \pm 0.6$ \\
\hline \multirow[t]{2}{*}{ II/II } & $24 / 24$ & $10.5 \pm 2.3$ & $4.0 \pm 0.06$ & $3.2 \pm 0.1^{*}$ & $8.2 \pm 0.9$ & $5.5 \pm 0.6$ \\
\hline & $P$ & NS & NS & $<0.001$ & $<0.001$ & $<0.005$ \\
\hline
\end{tabular}

Values are means $\pm \mathrm{SE}$. Number of experiments $=6$. Mean tubule length $=0.45 \pm 0.04 \mathrm{~mm} . P$ values are for $4 \mathrm{~K}$ vs. $24 \mathrm{~K}$ (paired $t$ test). Table headings, NS and * as in Table II.

sults demonstrate that changes in potassium concentration are able to modify total ammonia transport in the medullary thick ascending limb of the rat in vitro. Increasing the potassium concentration in luminal and bathing solutions reduced both the rate of total ammonia absorption and the steady state transepithelial $\mathrm{NH}_{4}^{+}$concentration gradient. The inhibition of total ammonia absorption was reversible and occurred when potassium replaced either sodium or $N$-methyl-D-glucamine, indicating that it is the increase in potassium concentration, rather than the reduction in the substituted cation, that acts to reduce ammonia absorption. These findings indicate that a direct effect of potassium concentration on renal tubule ammonia transport is an additional and potentially important mechanism that can contribute to the relation between potassium balance and urinary ammonium excretion. In particular, changes in potassium intake may regulate ammonia absorption in the medullary thick ascending limb and loop of Henle.

\section{Role of medullary thick ascending limb in ammonium excretion}

Ammonia recycling. It is generally recognized that transfer of ammonia from the loops of Henle to the collecting ducts in the renal medulla is an important process facilitating renal ammonium excretion $(4,14-16)$. This transfer process involves reabsorption of ammonia from the loops of Henle and accumulation of ammonia to high concentrations in the medullary interstitium $(4,17-20)$. Because secretion of ammonia by the collecting ducts depends on the $\mathrm{NH}_{3}$ concentration difference between the interstitial fluid and the collecting duct lumen $(4,17,21,22)$, the ability of the kidney to accumulate
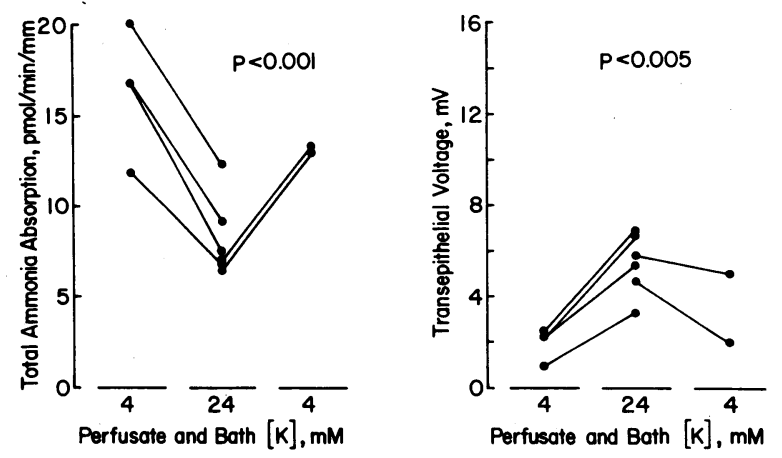

Figure 4. Effects of increasing potassium concentration on total ammonia absorption rate and transepithelial voltage in medullary thick ascending limbs. Closed circles, lines, and $P$ values as in Fig. 1. ammonia in the medulla and maintain a high medullary interstitial $\mathrm{NH}_{3}$ concentration is an important factor in the maintenance of a high rate of total ammonia excretion. The high ammonia content of the renal medulla has been proposed to depend on countercurrent multiplication $(5,20,23)$. Direct evidence to support this possibility was provided when the thick ascending limb of Henle's loop was demonstrated to absorb $\mathrm{NH}_{4}^{+}$against a concentration gradient (5). Direct absorption of $\mathrm{NH}_{4}^{+}$by the medullary thick ascending limb generates a transepithelial concentration difference for total ammonia that constitutes a "single effect" for countercurrent multiplication of ammonia in the outer medulla. Ammonia reabsorbed from the thick ascending limb would reenter the proximal straight tubule or descending limb to complete the recycling process $(4,24,25)$. This process is analogous to the countercurrent exchanger for $\mathrm{NaCl}$ in that the small concentration difference generated across the medullary thick ascending limb is multiplied by countercurrent flow between the loops, resulting in an axial gradient for total ammonia. The importance of medullary ammonia accumulation as a factor determining the rate of ammonium excretion has been demonstrated in chronic metabolic acidosis (17), in osmotic diuresis $(19,20)$, and in the remnant kidney $(26)$. Since ammonium absorption by the medullary thick ascending limb would provide energy for the countercurrent process, factors which affect thick ascending limb ammonia transport would be expected to alter medullary ammonia recycling and ammonium excretion.

Effects of potassium. In previous micropuncture studies in normal rats, potassium concentration averaged $36 \mathrm{mM}$ in vasa recta plasma and $26 \mathrm{mM}$ at the bend of Henle's loop $(7,8)$. During chronic potassium loading, the potassium concentration rose to $43-54 \mathrm{mM}$ in the vasa recta and to $36 \mathrm{mM}$ in Henle's loop $(6,7)$. During potassium depletion, the concentration fell to $5-10 \mathrm{mM}$ in both structures $(6,8)$. These results demonstrate that the potassium concentration in the medullary interstitium and loop of Henle varies over a wide range during changes in potassium balance and that the concentration tends to change in parallel in the two compartments. The exact potassium concentrations present in the outer medulla are not known. However, based on the values reported above for the inner medulla, it is likely that the potassium concentrations used in the present study (4-24 mM) represent a reasonable estimate of the physiological range of values that would be expected to surround the medullary thick ascending limb in vivo.

The results of the present study are consistent with the hypothesis that changes in potassium balance would alter am- 
monia recycling and transfer within the renal medulla. During conditions associated with potassium retention and hyperkalemia, the marked increase in potassium concentration in the medullary interstitium and loop of Henle would inhibit absorption of $\mathrm{NH}_{4}^{+}$by the medullary thick ascending limb and reduce the transepithelial $\mathrm{NH}_{4}^{+}$concentration difference generated across the tubule wall. The reduction in $\mathrm{NH}_{4}^{+}$absorption rate and the reduction in the transepithelial $\mathrm{NH}_{4}^{+}$concentration gradient would limit the extent of countercurrent multiplication and diminish accumulation of ammonia in the interstitium of the outer medulla. The lower interstitial $\mathrm{NH}_{3}$ concentration could impair secretion of ammonia into the medullary collecting ducts and decrease net ammonium excretion. During potassium depletion, opposite effects, mediated by a decrease in medullary potassium concentration, would cause ammonium excretion to increase.

The effects of potassium concentration on medullary thick ascending limb ammonium transport would act in conjunction with other renal effects to promote changes in ammonium excretion during changes in potassium balance. During potassium depletion, at least three factors would act to enhance ammonium excretion: $(a)$ an increase in ammonium production and secretion by proximal tubules which increases luminal ammonium concentration and ammonium delivery to the ascending limbs $(3,18,27,28),(b)$ a decrease in potassium concentration in the medullary interstitium and loops of Henle $(6,8)$ that would enhance $\mathrm{NH}_{4}^{+}$absorption by the medullary thick ascending limbs (Fig. 1), and (c) a decrease in medullary blood flow (29) that would enhance the capture of ammonia in the medulla. Taken together, these effects would act in an efficient and cooperative manner to promote countercurrent trapping of ammonia in the renal medulla and provide optimal conditions for collecting duct ammonia secretion and urinary ammonium excretion. During potassium retention, a decrease in ammonia production $(3,30,31)$, a decrease in medullary thick ascending limb $\mathrm{NH}_{4}^{+}$absorption (Fig. 1), and possibly an increase in medullary blood flow (3) would act in concert to reduce medullary ammonia accumulation and ammonium excretion. Although the relation between systemic potassium balance and ammonium excretion is well established, there have been no studies that have examined directly effects of potassium balance on ammonia transport in the renal medulla. Accordingly, further in vivo studies will be required to test the hypothesis that changes in potassium balance affect ammonium excretion by altering medullary ammonia recycling and transfer of ammonia from loops of Henle to medullary collecting ducts.

The present study provides no information regarding the mechanism by which potassium concentration affects ammonia transport. Preliminary experiments in this laboratory (32) have shown that changes in potassium concentration have no effect on bicarbonate transport in the medullary thick ascending limb. This indicates that the change in total ammonia transport did not occur as an indirect result of a change in luminal $\mathrm{pH}$ and must have been due to a direct effect of potassium concentration on $\mathrm{NH}_{4}^{+}$transport (32). Direct absorption of $\mathrm{NH}_{4}^{+}$by the thick ascending limb has been proposed to occur by at least two mechanisms $(5,33)$ : $(a)$ passive, paracellular absorption driven by the lumen-positive transepithelial voltage, and $(b)$ secondary-active absorption mediated by substitution of $\mathrm{NH}_{4}^{+}$for $\mathrm{K}^{+}$on the apical membrane $\mathrm{Na}-\mathrm{K}-2 \mathrm{Cl}$ cotransport system. The finding that changes in potassium concentration did not significantly alter the transepithelial voltage suggests that the transcellular rather than the paracellular pathway may have been affected. However, further studies of transepithelial and membrane voltages, as well as ammonia permeabilities, will be required to assess this possibility directly.

Effects of luminal flow rate. Results of the present study also demonstrate that absorption of ammonia by the medullary thick ascending limb was highly dependent on tubule fluid flow rate. The total ammonia absorption rate at $10 \mathrm{nl} / \mathrm{min}$ per $\mathrm{mm}$ was four times that measured at $2 \mathrm{nl} / \mathrm{min}$ per $\mathrm{mm}$ (Tables II and VI). These flow rates are within the physiological range of values (3-8 $\mathrm{nl} / \mathrm{min}$ ) measured previously in rats at the bend of Henle's loop $(17,18,34-36)$, indicating that flow rate is likely to be an important factor influencing ammonium absorption in the thick ascending limb in vivo. At least two factors could contribute to the flow dependence of ammonium absorption. First, an increase in flow rate was associated with an increase in total ammonia concentration in the collected fluid (Tables II and VI). The increase in mean luminal total ammonia concentration would increase the chemical driving force for $\mathrm{NH}_{4}^{+}$absorption. Second, the fall in luminal bicarbonate concentration that occurs normally in this segment as a result of luminal acidification $(5,10)$ would be minimized at the higher flow. The higher lumen $\mathrm{pH}$, in conjunction with the higher total ammonia concentration, would result in a higher luminal $\mathrm{NH}_{3}$ concentration when flow rate was increased. The higher luminal $\mathrm{NH}_{3}$ concentration would decrease the transepithelial concentration gradient favoring $\mathrm{NH}_{3}$ backflux from bath to lumen (33) and increase the net rate of total ammonia absorption. Increasing the flow rate also caused a small decrease in the lumen-positive transepithelial voltage, an effect that would inhibit passive, paracellular $\mathrm{NH}_{4}^{+}$absorption (5). Because the total ammonia absorption rate increased, it appears that the flow-related changes acting to enhance ammonia absorption were more important than the decrease in transepithelial voltage.

The flow-dependence of medullary thick ascending limb ammonium absorption could play a role in promoting changes in ammonium excretion during acid-base disturbances. In rats with chronic metabolic acidosis, luminal flow rate was increased at the bend of Henle's loop (37) and in the early distal tubule $(38,39)$, consistent with an increase in flow in the thick ascending limb. Also, Roy et al. observed in rats that luminal flow rate at the end of the descending limb varied inversely with the plasma bicarbonate concentration (40). If the rate of ammonium absorption by the thick ascending limb is a function of the transepithelial ammonium concentration difference, then during acidosis the increase in flow rate would maintain a higher concentration of total ammonia in the luminal fluid and enhance ammonium absorption. As discussed above, a high rate of thick ascending limb ammonium absorption would enhance ammonium excretion by promoting increased medullary ammonia accumulation and collecting duct ammonia secretion.

In summary, the results of these experiments demonstrate that both potassium concentration and luminal flow rate are important determinants of the rate of total ammonia absorption by the medullary thick ascending limb of the rat. Increasing potassium concentration in the luminal and bathing solutions inhibits total ammonia absorption and reduces the steady-state transepithelial $\mathrm{NH}_{4}^{+}$concentration gradient. In- 
creasing the luminal flow rate significantly increases the rate of total ammonia absorption. It is proposed that direct effects of potassium concentration on medullary thick ascending limb ammonium transport can contribute to the relation between systemic potassium balance and renal ammonium excretion. Potassium loading and hyperkalemia may reduce ammonium excretion, in part, by inhibiting $\mathrm{NH}_{4}^{+}$absorption in the medullary thick ascending limb and impairing transfer of ammonia from loops of Henle to collecting ducts in the renal medulla. Conversely, potassium depletion may stimulate $\mathrm{NH}_{4}^{+}$absorption by the medullary thick ascending limb, enhance medullary ammonia recycling, and promote increased collecting duct ammonia secretion and urinary ammonium excretion.

\section{Acknowledgments}

The author thanks Dr. Thomas D. DuBose, Jr. for his advice and continued support and Dr. Robert Beach for helpful suggestions on the manuscript. The assistance of Nancy Tovar in preparation of the manuscript also is appreciated.

This research was supported by a Grant-In-Aid from the American Heart Association with funds contributed in part by the American Heart Association, Texas Affiliate, Inc., and by BRSG 2 SO7 RR05427-24 awarded by the Biomedical Research Support Grant Program, Division of Research Resources, National Institutes of Health.

\section{References}

1. Tannen, R. L. 1986. Potassium disorders. In Fluids and Electrolytes. J. P. Kokko and R. L. Tannen, editors. W. B. Saunders Co., Philadelphia. 150-228.

2. Cogan, M. G., and F. C. Rector, Jr. 1986. Acid-base disorders. In The Kidney. B. M. Brenner and F. C. Rector, Jr., editors. 3rd ed. W. B. Saunders Co., Philadelphia. 457-517.

3. Tannen, R. L. 1977. Relationship of renal ammonia production and potassium homeostasis. Kidney Int. 11:453-465.

4. Good, D. W., and M. A. Knepper. 1985. Ammonia transport in the mammalian kidney. Am. J. Physiol. 248 (Renal Fluid Electrolyte Physiol. 17):F459-F471.

5. Good, D. W., M. A. Knepper, and M. B. Burg. 1984. Ammonia and bicarbonate transport by thick ascending limb of rat kidney. $\mathrm{Am}$. J. Physiol. 247 (Renal Fluid Electrolyte Physiol. 16):F35-F44.

6. Diezi, J., P. Michoud, J. Aceves, and G. Giebisch. 1973. Micropuncture study of electrolyte transport across papillary collecting duct of the rat. Am. J. Physiol. 224:623-634.

7. Battilana, C. A., D. C. Dobyan, F. B. Lacy, J. Bhattacharya, P. A. Johnston, and R. L. Jamison. 1978. Effect of chronic potassium loading on potassium secretion by the pars recta or descending limb of the juxtamedullary nephron in the rat. J. Clin. Invest. 62:1093-1103.

8. Dobyan, D. C., F. B. Lacy, and R. L. Jamison. 1979. Suppression of potassium-recycling in the renal medulla by short-term potassium deprivation. Kidney Int. 16:704-709.

9. Garvin, J., and M. A. Knepper. 1987. Bicarbonate and ammonia transport in isolated, perfused rat proximal straight tubules. Am. J. Physiol. 253 (Renal Fluid Electrolyte Physiol. 22):F277-F281.

10. Good, D. W. 1985. Sodium-dependent bicarbonate absorption by cortical thick ascending limb of rat kidney. Am. J. Physiol. 248 (Renal Fluid Electrolyte Physiol. 17): F821-F829.

11. Good, D. W., and G. G. Vurek. 1983. Picomole quantitation of ammonia by flow-through fluorometry. Anal. Biochem. 130:199-202.

12. Sasaki, S., and M. Imai. 1980. Effects of vasopressin on water and $\mathrm{NaCl}$ transport across the in vitro perfused medullary thick ascending limb of Henle's loop of mouse, rat and rabbit kidneys. Pfluegers Arch. 383:215-221.

13. Work, J., J. H. Galla, B. B. Booker, J. A. Schafer, and R. G. Luke. 1985. Effect of ADH on chloride reabsorption in the loop of
Henle of the Brattleboro rat. Am. J. Physiol. 249 (Renal Fluid Electrolyte Phyisol. 18):F698-F703.

14. Alpern, R. J., D. G. Warnock, and F. C. Rector, Jr. 1986. Renal acidification mechanisms. In The Kidney. B. M. Brenner and F. C. Rector, Jr., editors. Third ed. W. B. Saunders Co., Philadelphia. 206-249.

15. Pitts, R. F. 1973. Production and excretion of ammonia in relation to acid-base regulation. In Handbook of Physiology. Section 8. Renal Physiology. J. Orloff and R. W. Berliner, editors. American Physiological Society, Washington, DC. 455-496.

16. Halperin, M. L., M. B. Goldstein, B. J. Stinebaugh, and R. L. Jungas. 1985. Biochemistry and physiology of ammonium excretion. In The Kidney: Physiology and Pathophysiology. D. W. Seldin and G. Giebisch, editors. Raven Press, New York. 1471-1490.

17. Good, D. W., C. R. Caflisch, and T. D. DuBose, Jr. 1987. Transepithelial ammonia concentration gradients in inner medulla of the rat. Am. J. Physiol. 252 (Renal Fluid Electrolyte Physiol. 21):F491-F500.

18. Buerkert, J., D. Martin, and D. Trigg. 1982. Ammonium handling by superficial and juxtamedullary nephrons in the rat. Evidence for an ammonia shunt between the loop of Henle and the collecting duct. J. Clin. Invest. 70:1-12.

19. Stern, L., K. A. Backman, and J. P. Hayslett. 1985. Effect of cortical-medullary gradient for ammonia on urinary excretion of ammonia. Kidney Int. 27:652-661.

20. Robinson, R. R., and E. E. Owen. 1965. Intrarenal distribution of ammonia during diuresis and antidiuresis. Am. J. Physiol. 208:1129-1134.

21. Knepper, M. A., D. W. Good, and M. B. Burg. 1985. Ammonia and bicarbonate transport by rat cortical collecting ducts perfused in vitro. Am. J. Physiol. 249 (Renal Fluid Electrolyte Phyisol. 18):F870F877.

22. Hamm, L. L., D. Trigg, D. Martin, C. Gillespie, and J. Buerkert. 1985. Transport of ammonia in the rabbit cortical collecting tubule. J. Clin. Invest. 75:478-485.

23. Sullivan, L. P. 1965. Ammonia secretion during stopped flow: A hypothetical ammonium countercurrent system. Am. J. Physiol. 209:273-282.

24. Garvin, J. L., M. B. Burg, and M. A. Knepper. 1987. $\mathrm{NH}_{3}$ and $\mathrm{NH}_{4}^{+}$transport by rabbit renal proximal straight tubules. Am. J. Physiol. 252 (Renal Fluid Electrolyte Physiol. 21):F232-F239.

25. Kurtz, I., R. Star, R. S. Balaban, J. L. Garvin, and M. A. Knepper. 1986. Spontaneous luminal disequilibrium $\mathrm{pH}$ in $\mathrm{S}_{3}$ proximal tubules. Role in ammonia and bicarbonate transport. J. Clin. Invest. 78:989-996.

26. Buerkert, J., D. Martin, D. Trigg, and E. Simon. 1983. Effect of reduced renal mass on ammonium handling and net acid formation by the superficial and juxtamedullary nephron of the rat. J. Clin. Invest. 71:1661-1675.

27. Jaeger, P., B. Karlmark, and G. Giebisch. 1983. Ammonium transport in rat cortical tubule: relationship to potassium metabolism. Am. J. Physiol. 245 (Renal Fluid Electrolyte Physiol. 14):F593-F600.

28. Nonoguchi, H., Y. Takehara, and H. Endou. 1986. Intra- and inter-nephron heterogeneity of ammoniagenesis in rats. Effects of chronic metabolic acidosis and potassium depletion. Pfluegers Arch. 407:245-251.

29. Whinnery, M., and R. T. Kunau, Jr. 1979. Effect of potassium deficiency on papillary plasma flow in the rat. Am. J. Physiol. 237:F226-F231.

30. Sastrasinh, S., and R. L. Tannen. 1983. Effect of potassium on renal $\mathrm{NH}_{3}$ production. Am. J. Physiol. 244 (Renal Fluid Electrolyte Physiol. 13):F383-F391.

31. Sleeper, R. S., P. Belanger, G. Lemieux, and H. G. Preuss. 1982. Effects of in vitro potassium on ammoniagenesis in rat and canine kidney tissue. Kidney Int. 21:345-353.

32. Good, D. W. 1987. Effects of potassium concentration on ammonium transport by medullary thick ascending limb. Kidney Int. 31:408. 
33. Good, D. W., M. A. Knepper, and M. B. Burg. 1985. Ammonia absorption by the thick ascending limb of Henle's loop. In Contributions to Nephrology. Vol. 47. Karger, Basel. 110-115.

34. Jamison, R. L. 1970. Micropuncture study of superficial and juxtamedullary nephrons in the rat. Am. J. Physiol. 218:46-55.

35. Gelbart, D. R., C. A. Battilana, J. Bhattacharya, F. B. Lacy, and R. L. Jamison. 1978. Transepithelial gradient and fractional delivery of chloride in thin loop of Henle. Am. J. Physiol. 235 (Renal Fluid Electrolyte Physiol. 4):F192-F198.

36. Higashihara, E., J. B. Stokes, J. P. Kokko, W. B. Campbell, and T. D. DuBose, Jr. 1979. Cortical and papillary micropuncture examination of chloride transport in segments of the rat kidney during inhibition of prostaglandin production. A possible role for prostaglandins in the chloruresis of acute volume expansion. J. Clin. Invest. 64:12771287.
37. Buerkert, J., D. Martin, and D. Trigg. 1983. Segmental analysis of the renal tubule in buffer production and net acid formation. Am.J. Physiol. 244 (Renal Fluid Electrolyte Physiol. 13):F442-F454.

38. Simon, E., D. Martin, and J. Buerkert. 1985. Contribution of individual superficial nephron segments to ammonium handling in chronic metabolic acidosis in the rat. Evidence for ammonia disequilibrium in the renal cortex. J. Clin. Invest. 76:855-864.

39. Sajo, I. M., M. B. Goldstein, H. Sonnenberg, B. J. Stinebaugh, D. R. Wilson, and M. L. Halperin. 1981. Sites of ammonia addition to tubular fluid in rats with chronic metabolic acidosis. Kidney Int. 20:353-358.

40. Roy, D. R., K. L. Blouch, and R. L. Jamison. 1982. Effects of acute acid-base disturbances on $\mathrm{K}$ delivery to the juxtamedullary enddescending limb. Am. J. Physiol. 243 (Renal Fluid Electrolyte Physiol. 12):F188-F196. 